\title{
The Contribution of Higher Education Institutions to the SDGs-An Evaluation of Sustainability Reporting Practices
}

\author{
Fabio Caputo *(D), Lorenzo Ligorio (D) and Simone Pizzi (D) \\ Dipartimento di Scienze dell'Economia, Università del Salento, 73100 Lecce, Italy; \\ lorenzo.ligorio@unisalento.it (L.L.); simone.pizzi@unisalento.it (S.P.) \\ * Correspondence: fabio.caputo@unisalento.it
}

Citation: Caputo, Fabio, Lorenzo Ligorio, and Simone Pizzi. 2021. The Contribution of Higher Education Institutions to the SDGs-An Evaluation of Sustainability Reporting Practices. Administrative Sciences 11: 97. https://doi.org/ 10.3390/admsci11030097

Received: 30 July 2021

Accepted: 2 September 2021

Published: 7 September 2021

Publisher's Note: MDPI stays neutral with regard to jurisdictional claims in published maps and institutional affiliations.

Copyright: (c) 2021 by the authors. Licensee MDPI, Basel, Switzerland. This article is an open access article distributed under the terms and conditions of the Creative Commons Attribution (CC BY) license (https:// creativecommons.org/licenses/by/ $4.0 /)$

\begin{abstract}
The introduction of Agenda 2030 has impacted the public and private sectors. Agenda 2030 is a document that aims to promote collaboration and partnership between countries and the population for the achievement of 17 SDGs, which cover all the three dimensions of sustainability: environmental, social, and economic. Within the public organizations, higher education institutions (HEIs) have shown certain attention on the topic. In particular, for many HEIs, the publication of sustainability reports has represented an instrument to disclose and publicize their commitment to the 17 Sustainable Development Goals (SDGs). To shed light on the highly fragmented panorama of the disclosure of SDGs in the context of HEIs, the present study employed a content analysis on publicly available sustainability reports published only by the HEIs that adopted the GRI Standards as reporting guidelines. The results show the centrality of the social and environmental issues within the disclosed information. Moreover, the provision of a thematic analysis on the SDGs disclosure sections revealed the interest of the sampled HEIs in increasing the level of involvement of their stakeholders.
\end{abstract}

Keywords: Sustainable Development Goals; higher education; sustainability reporting; Global Reporting Initiative; thematic analysis

\section{Introduction}

In the last few years, many Governments have enhanced their contribution to sustainable development by implementing new policies that would promote the achievement of the 17 Sustainable Development Goals (SDGs) defined by the United Nations in Agenda 2030 (Bebbington and Unerman 2018). In this sense, this paradigm shift favored the identification of public strategies in order to mitigate the negative externalities of emerging and old topics such as climate change, social inequalities, and discrimination (Sachs et al. 2019). In addition, many project appraisals performed by governments integrate sustainable and ethical principles (European Commission 2014). Thus, contrary to the past (Steurer et al. 2012; Venturelli and Caputo 2017), sustainable development has played a central role in social and economic debates (Carroll 2021).

The SDGs theoretically represent the follow-up to the Millennium Development Goals (MDGs). However, building on the main critical insights collected by the United Nations regarding MDGs, Agenda 2030 is characterized by the direct involvement of unconventional stakeholders such as companies and higher education institutions (HEIs) (Cottafava et al. 2019; Pizzi et al. 2020). The achievement of the MDGs was limited by the absence of systemic policies inspired by a common vision with regard to sustainable development (Jain and Islam 2015; Sachs 2012). Thus, the 17 SDGs considered both the potential contribution made by governments and regulators, and the potential contribution made by other stakeholders (Scheyvens et al. 2016).

The implementation of entrepreneurial ecosystems that are inspired by sustainable principles requires the development of common strategies and synergies with HEIs. Academics and policymakers consider HEIs as an enabler for an effective, sustainable transition 
by organizations (Burke and Demirag 2015; Nicolò 2020). Furthermore, HEIs are also strategic stakeholders in the achievement of the SDGs through their initiatives. In this sense, their contributions are twofold. On the one hand, they contribute to the SDGs through their teaching and research activities. On the other hand, they contribute to the SDGs through their strategies and initiatives.

Building on the preliminary considerations shown above, this paper explores the non-financial reports published by HEIs in the official database released by the Global Reporting Initiative. In particular, the present contribution aims to understand the level of HEI contribution to Agenda 2030 through the disclosure of SDGs. In these terms, the first objective of the study is linked to the identification of the most disclosed SDGs in HEI reports. Moreover, to deepen the knowledge of the HEIs' SDGs disclosure, the study explores the content of the collected disclosures.

Despite the theoretical misalignment between corporate communication and action (Lee and Hageman 2018), an empirical assessment of the GRI Content Indexes was conducted to evaluate the main contribution provided by HEIs to Agenda 2030. Following the methodological approach used in prior studies on SDG Reporting (Avrampou et al. 2019; García Meca and Ferrero 2021; Pizzi et al. 2021), the score was built according to the latest guidelines released by the SDG Compass (Global Reporting Initiative 2017). Furthermore, to avoid the risks related to the analysis of synthetic indicators, a thematic analysis (Jackson and Bazeley 2020) was conducted to collect qualitative insights into the main contents disclosed by the HEIs.

The present study has been structured as follows. The following section presents the background of the research. Next, methods of the analysis are described. Subsequently, the results are presented. Finally, a discussion of the results and conclusions are provided.

\section{Background}

\subsection{Sustainability in Public Organizations}

The increasing relevance of sustainability topics has involved multiple institutions around the world. Specifically, covering a central position in providing goods and services to the population (F Caputo and Di Cagno 2010), public sector entities have shown a particular concern towards environmental and social issues (Brammer and Walker 2011; GBS 2005). Such new interest has also been linked with the introduction of performance measurements and the adoption of sustainability indicators (Fabio Caputo et al. 2017). In these terms, Carol Adams et al. (2014) revealed that the introduction of such measures was primarily interested in social issues such as gender diversity and employee health.

The introduction and the disclosure of sustainability measures have also interested the public sector on multiple levels. Local governments have started disclosing sustainability information through their websites to promote and legitimize their activities within the communities (Navarro Galera et al. 2014). In this sense, public entities respond to the increasing pressures that they receive from various stakeholders such as communities, employees, and corporations (Midin et al. 2017).

Thus, the different interests and pressures coming from the stakeholder's audience have led to the heterogeneous spread of sustainability practices within the public sector (Esposito et al. 2021). In particular, a relevant interest in introducing sustainability practices and disclosures has been shown by hybrid organizations. Hybrid organizations can be identified as entities owned by the public and private shareholders and are established to provide public services and goods (Alexius and Grossi 2018; Voorn et al. 2017). Within the hybrid environment, it is possible to identify multiple types of services provided. In particular, Etse et al. (2021) revealed how the organizations involved in healthcare and education are the most interested in adopting sustainability practices even though their adoption is still considered at an early stage. 


\subsection{The Adoption of Sustainability Reporting in HEIs}

Linked to the sustainability actions, the phenomenon of sustainability reporting has been interesting to multiple organizations (Adhikariparajuli et al. 2021; GBS 2008). Specifically, HEIs have mainly been involved in such practice because of their central role in sensitizing communities towards social and environmental topics, and the relevant role HEIs have in shaping future work figures (Ceulemans et al. 2015; Gulluscio and Torrecchia 2017; Manes Rossi et al. 2018). In this context, many organizations have conducted studies and research to identify paradigms and frameworks that are useful for the assessment of the real contribution provided by the HEIs to sustainable development. In particular, according to the Italian University Network for Sustainable Development (RUS) and the Gruppo di Studio per il Bilancio Sociale (GBS), the contribution provided by the HEIs to the SDGs are twofold (RUS and GBS 2021). The first contribution consists of the sum of the externalities related to the inclusion of CSR courses in their curricula. As regards the second contribution, they also identified potential contributions related to the adoption of sustainable and ethical behaviors. In this sense, HEIs could support the transition toward a more sustainable planet through direct and indirect contributions.

Measuring the quality of sustainability reporting of HEIs has been the subject of debate in the literature. First, Lozano (2006) proposed a framework of analysis to explore the information disclosed by HEIs while considering the significant differences that emerge from the various HEI reports. In addition, the author suggested that the most suitable and relevant disclosure standards are identified in the Global Reporting Initiative guidelines. On the same idea, Alonso-Almeida et al. (2015) and Aversano et al. (2020) confirmed that HEIs are committed to pursuing sustainability goals and that sustainability reporting is the valuable tool they are adopting to respond to the increasing pressure from stakeholders. Likewise, the authors revealed that the GRI guidelines for sustainability reporting are the most suitable guidelines for HEIs and that European institutions are the early adopters of such standards. However, the study also showed the panorama's relevant fragmentation and the difficulties linked with the comparability of the complying HEIs. In these terms, Brusca et al. (2018) approached the issue through a case analysis of an innovative Spanish university. Consequently, it was revealed that apart from the aim of legitimization of sustainability reporting, the HEIs managed to increase their competitive advantage by improving their levels of transparency (Brusca et al. 2020). Such a new point of view on the role of the HEIs' sustainability disclosure is shared by Sassen and Azizi (2018), who confirmed that the stakeholders' pressure is the most relevant driver of disclosure. In addition, the study pointed out that HEIs are also influenced by governments' decisions and their request for increasing transparency.

Thus, this shows how prior studies have analyzed the two sides of HEIs and sustainability reporting. The exploration has uncovered multiple issues and gaps, mostly linked with the absence of a common framework for disclosing sustainability information. In particular, the literature revealed how the tremendously diverse HEI environments create an issue of comparability. In this sense, Sepasi et al. (2019) suggested is the need to provide a more holistic view of the HEI disclosures panorama in order to identify the core topics driving the publication of sustainability reports. With this in mind, Alonso-Almeida et al. (2015) clarified that the GRI guidelines as a standard reporting tool within HEIs can be seen as a possible means for developing a longitudinal and comprehensive study to explore the topic.

\subsection{The Contribution of HEIs to the SDGs}

In line with the increasing relevance of sustainability reporting practices within the HEI environment, in recent years, literature has shown interest in the role of the Agenda 2030 Sustainable Development Goals and the relevance they have within HEIs (Filho et al. 2020). Covering the three dimensions of sustainability, the 17 SDGs build on the previous Millennium Development Goals (MDGs) and seek to accomplish what has not been achieved. In particular, the 17 SDGs and the 169 associated targets try to promote 
human rights, gender equality, and the empowerment of all women and girls (United Nations 2015). The interest revolving around the SDGs is linked with the informative role that such goals have. As Salvia et al. (2019) revealed, SDG disclosure study allows for an understanding of the most relevant concerns of a country about society and the environment. Moreover, Agenda 2030 has recognized education as a central driver of change, thus making the role of HEIs pivotal in the pursuit of its goals (Venturelli et al. 2019b). However, it has emerged how the HEIs' disclosure practices are an evolving environment (An et al. 2017), and there is a gap in the understanding of how the different scenarios impact the disclosure of SDGs (Beynaghi et al. 2016).

The role of SDGs in HEIs has also seen different declinations. Specifically, Cottafava et al. (2019) revealed how the inclusion of SDG training programs significantly improves the sustainable development strategy of the HEIs and allows for an increase in the transparency of the institutions through the deeper connection and involvement of stakeholders. In addition, many universities have started to integrate sustainable principles in their strategic plans due to the increasing awareness of the social role represented by HEIs (Di Nauta et al. 2020). In these terms, Leal Filho et al. supported the relevance of the SDGs in HEIs and suggested a framework for a more effective implementation of the goals in teaching and research as well as in operational activities. Furthermore, a case study developed by Raji and Hassan (2021) highlighted that reporting activities mitigate the asymmetries between HEIs and stakeholders.

This evidence demonstrates that research on SDGs and HEIs is emerging as a relevant topic in the literature and has raised different questions (De La Poza et al. 2021; GarcíaFeijoo et al. 2020; Pizzi et al. 2020). Specifically, the SDG disclosure by HEIs has been explored from a single point of view, leaving open the debate on the multiple university contexts involved in Agenda 2030 (Saha et al. 2021). Furthermore, an understanding of the SDG orientation within the HEI context is required in order to be able to provide future guidelines for the implementation of Agenda 2030, both in sustainability strategies and in teaching (Leal Filho et al. 2019a).

\section{Methods}

To explore the HEIs' contribution to Agenda 2030 through their sustainability reporting, the present study adopted the approach proposed in prior studies for non-financial reporting (Bellucci and Manetti 2017; Venturelli et al. 2019a). More specifically, the Global Reporting Initiative Database was used to identify the HEIs with published sustainability reports (Sannino et al. 2020). This database allows for the examination of reports published in the past years by companies that have adopted the GRI guidelines in their disclosures (https: / / database.globalreporting.org/, accessed on 30 July 2021).

The search query was set to include only HEIs compliant with the GRI standard guidelines in these terms. In particular, we selected all the companies classified by the GRI as "universities". In order to increase the comparability of the cases, a single year was considered; thus, reports published in the year of 2019 were chosen.

Subsequently, the study identified the SDGs disclosed by the sampled HEIs in their sustainability reports. Specifically, similar to Avrampou et al. (2019), the SDG Compass guidelines were used to link the disclosed GRI indicators with the 17 SDGs and to create a final related score. The SDG Compass is a document released by the Global Reporting Initiative that helps preparers to include the SDGs within the sustainability reports by creating a bridge between single GRI indicators and each Agenda 2030 goal.

In these terms, content analysis was used to identify the disclosed GRI indicators. Content analysis is a widely adopted method in accounting studies (Krippendorff 2018), and in this study, it was structured into three steps. First, the units of analysis were identified in the sustainability reports published by the HEIs on their websites. Subsequently, the units were codified, adopting the SDG Compass as the framework for analysis (GRI 2020). In particular, a dichotomic variable was associated with each GRI indicator to identify the level of HEI compliance. Finally, the results were analyzed. 
Following the SDG Compass document, the present study considered 163 GRI indicators to identify the different SDGs disclosed in the reports (Table 1). As can be seen in the table below, some goals (such as goals 8 and 16) show a more significant number of indicators. Accordingly, the score was elaborated as a mean value of the dichotomic variables in order to facilitate comparability among the results.

Table 1. Number of GRI indicators per SDG.

\begin{tabular}{ccc}
\hline SDG & Definition & GRI Indicators \\
\hline 1 & No poverty & 3 \\
2 & Zero hunger & 2 \\
3 & Good health and well-being & 12 \\
4 & Quality education & 1 \\
5 & Gender equality & 13 \\
6 & Clean water and sanitation & 11 \\
7 & Affordable and clean energy & 4 \\
8 & Decent work and economic growth & 29 \\
9 & Industry, innovation, and infrastructure & 2 \\
10 & Reduced inequalities & 5 \\
11 & Sustainable cities and communities & 1 \\
12 & Responsible consumption and production & 17 \\
13 & Climate change & 11 \\
14 & Life below water & 13 \\
15 & Life on land & 12 \\
16 & Peace, justice, and strong institutions & 23 \\
17 & Partnerships for the goals & 4 \\
\hline
\end{tabular}

To increase the reliability of the analysis, two independent researchers carried out the codification to avoid inter-coder issues (Krippendorff 2018; Michelon et al. 2019).

Subsequently, following Pizzi et al. (2020), an SDG reporting score was realized by elaborating the mean value of the dichotomic variables belonging to the specific goals, as follows:

$$
S R_{\text {score }}=\frac{\sum_{n}^{1} \text { GRI INDICATORS DISCLOSED }}{\text { GRI INDICATORS REQUIRED BY SDG COMPASS }}
$$

In addition, following Avrampou et al. (Avrampou et al. 2019), the codified data were processed to identify the most relevant disclosed topics related to the SDG disclosure. The identification of the disclosed topics provided a more comprehensive overview of the selected HEIs' commitment to the SDGs and offered a ranking of the most significant topics in HEI reporting.

Finally, to provide further evidence to the present study and to provide a description of the selected subjects, information related to the sampled HEIs was collected from the GRI database. In particular, the location and size were extracted.

To develop the study, the qualitative analysis software Nvivo 12 was adopted to codify the collected units of analysis (Edwards-Jones 2014).

\section{Results}

\subsection{Descriptive Results}

The first step of the analysis was developed to provide the study with a descriptive overview of the sampled HEIs. Figure 1 below provides a geographical description of the selected sample of HEIs. The study revealed how the most significant part of the sample comes from European HEIs, representing 38\% of the entire sample. This is followed by South America, which shows a high density of HEIs and represents $28 \%$ of the entire sample. The last three areas show several HEIs below ten units. Specifically, with two HEIs in the analysis, the least represented area is Oceania $(7 \%)$. 


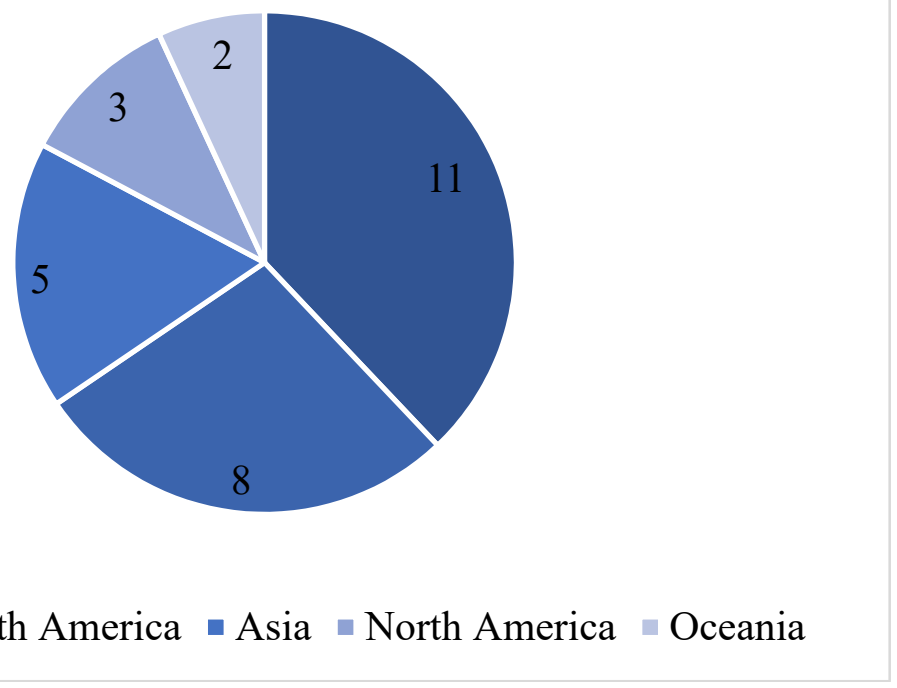

Figure 1. HEI distribution per geographical region.

Because of the wide variety of dimensions that characterize the HEI environment, the dimensional parameter provided by the database was included. In this sense, Table 2 provides an insight into the sample distribution concerning the dimension of the sampled HEIs, as defined by the Global Reporting Initiative database. In particular, the dimensional parameter offered by the online platform was built according to the local normative requirements on the size classification of each university. The table shows how the sample is almost equally divided between the large and small-medium-sized HEIs. Specifically, covering $59 \%$ of the total, the large HEIs appear to be interested in publishing sustainability reports. However, the sample does not show medium-sized HEIs, while the small-medium dimension represents $41 \%$ of the total sample. Ultimately, the sampling process revealed that small HEIs are not adopting the GRI guidelines.

Table 2. Size distribution.

\begin{tabular}{lcc}
\hline Size & N & $\%$ \\
\hline Large & 17 & $59 \%$ \\
Small-Medium & 12 & $41 \%$ \\
\hline Total & 29 & $100 \%$ \\
\hline
\end{tabular}

\subsection{GRI Indicators Disclosure}

Building on the SDG Compass tool, the present study collected insights into indicators of the GRI standards that were disclosed in the collected sustainability reports. Table 3 below shows the ten most relevant GRI indicators that the sampled HEIs included in their sustainability reports; these provide evidence on how the disclosure of specific GRI indicators impacts the contribution towards the SDGs.

Within the first five most disclosed indicators, it can be seen that three out of the five positions on the ranking are under the "general disclosures" indicators. Specifically, the most disclosed indicator is 102-8 "Information on employees and other workers", which was reported by $96 \%$ of the sampled HEIs. In addition, the relevance of indicator 102-8 is linked to the contribution towards goal 10, "Reduced inequalities", which appears to be a core topic in the university context. 
Table 3. Top 10 ranking of GRI Indicators.

\begin{tabular}{|c|c|c|c|}
\hline Rank & Standard & Definition & $\mathbf{N}$ \\
\hline 1 & $102-8$ & Information on employees and other workers & 28 \\
\hline 2 & $102-16$ & Values, principles, standards, and norms of behavior & 27 \\
\hline 3 & $302-1$ & Energy consumption within the organization & 26 \\
\hline 4 & $102-22$ & $\begin{array}{l}\text { Composition of the highest governance body and its } \\
\text { committees }\end{array}$ & 22 \\
\hline 5 & $\begin{array}{l}401-1 \\
201-1\end{array}$ & $\begin{array}{l}\text { New employee hires and employee turnover } \\
\text { Direct economic value generated and distributed }\end{array}$ & 21 \\
\hline 6 & $\begin{array}{l}303-1 \\
405-1\end{array}$ & $\begin{array}{l}\text { Water withdrawal by source } \\
\text { Diversity of governance bodies and employees }\end{array}$ & 19 \\
\hline 7 & 403-1 & $\begin{array}{l}\text { Workers representation in formal joint management } \\
\text { worker health and safety committees }\end{array}$ & 18 \\
\hline 8 & $\begin{array}{l}302-4 \\
302-3\end{array}$ & $\begin{array}{l}\text { Reduction of energy consumption } \\
\text { Energy intensity }\end{array}$ & 17 \\
\hline 9 & $\begin{array}{l}405-2 \\
406-1 \\
205-1 \\
305-4\end{array}$ & $\begin{array}{l}\text { Ratio of basic salary and remuneration of women to men } \\
\text { Incidents of discrimination and corrective actions taken } \\
\text { Operations assessed for risks related to corruption }\end{array}$ & \multirow{3}{*}{14} \\
\hline \multirow[t]{2}{*}{10} & $\begin{array}{l}305-4 \\
307-1\end{array}$ & $\begin{array}{c}\text { GHG emissions intensity } \\
\text { Non-compliance with environmental laws and } \\
\text { regulations }\end{array}$ & \\
\hline & $401-3$ & $\begin{array}{l}\text { Total number of employees that returned to work in the } \\
\text { reporting period after parental leave ended, by gender }\end{array}$ & \\
\hline
\end{tabular}

Furthermore, indicators 102-16 and 102-22, respectively "Values, principles, standards, and norms of behavior" and "Values, principles, standards, and norms of behavior", show a particular centrality in supporting goal 16, "Peace, justice and strong institutions", which acquires particular relevance in public entities such as the HEIs.

As a point of junction, GRI indicator 401-1, "New employee hires and employee turnover", which takes fifth place in the ranking, confirms the attention of HEIs towards the role of the employees. In particular, such information reveals how HEIs take part in the development of a country's economy by contributing to the pursuit of goal 8, "Decent work and economic growth".

At last, indicator 302-1, "Energy consumption within the organization", ranks third within the five most disclosed indicators and confirms that $90 \%$ of the sampled HEIs disclose relevant information towards their environmental impact in terms of emissions and energy consumption.

The second part of the GRI indicator ranking reveals how different indicators provided equal numbers of HEI disclosures. First, the disclosures of environmental indicators such as the 303-1, 302-4, 302-3, 305-4, and 307-1 confirm the HEIs' interest in contributing to biodiversity care and in responding to climate change issues. Specifically, the disclosures show how the HEIs are contributing to goals 6, 7, and 16, respectively "Water and sanitation", "Affordable and clean energy", and "Peace, justice, and strong institutions".

Furthermore, indicators 401-1, 405-1, and 403-1 suggest the HEIs' attention towards the quality of work and occupational health.

Finally, indicators 201-1 and 205-1, related to anti-corruption policies and economic performance, are linked to goal 8, "Decent work and economic growth".

\subsection{SDG Reporting Performance}

To understand the level of SDG disclosure within the considered HEI reports, the present study was developed by associating a dichotomic variable to each GRI indicator, linked by the SDG Compass document to each Agenda 2030 goal. The analysis revealed how the majority of the sample contributed to the SDGs. In particular, the mean value of the HEIs' SDG scores was found to be at 0.73 on a scale from 0 to 1 , where 0 relates to the absence of SDG-related indicators and 1 identifies complete compliance. From this point 
of view, the study shows that the "Ball State University" discloses all 17 SDGs. On the contrary, the "Liceo Salazar y Herrera" takes the last position in the sample (23.5\%).

The remaining part of the sample shows a good level of SDG disclosure by obtaining a mean value of 0.72 . The standard deviation analysis reveals a little variability within the different goals. Specifically, the mean value of 0.41 for the standard deviation and the mean value of the total scores in each university confirm how the indicators are equally disclosed within the reports. However, "Taipei University" and "Universidad Santiago de Chile" scored standard deviation values above the mean.

Regarding the SDGs disclosure, Figure 2 provides an overview of the disclosed goals. Specifically, an analysis of the 29 revealed how the most disclosed SDG is goal 4, "Quality education", which was reported by $72 \%$ of the entire sample of HEIs. The second most relevant goal is SDG 10, "Reduced inequalities", with a similar value (68\%). In third place is goal 9, "Industry, innovation, and infrastructure", which was disclosed by $55 \%$ of the sample.

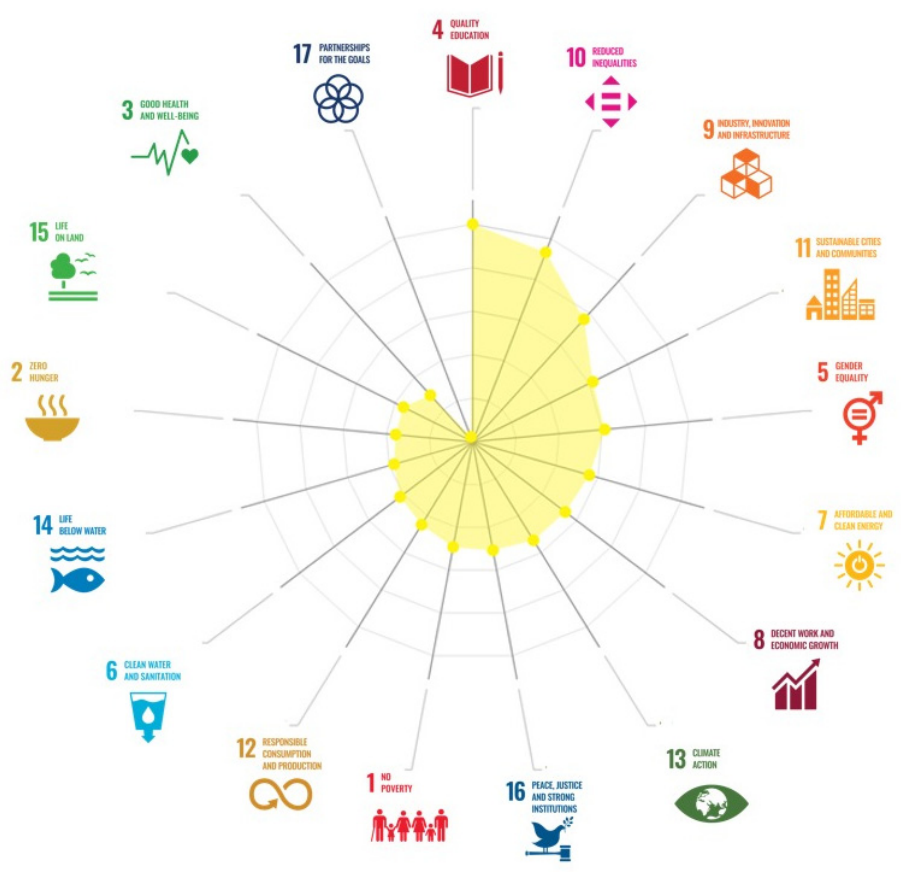

Figure 2. Radar graph of disclosed SDGs.

Taking into consideration the bottom part of the ranking, it can be observed that the least disclosed goal is goal 17, "Partnerships for the goals", which, as shown in Table 3, was disclosed by "Ball State University" and the "ETH Zurich". Subsequently, at second to the last place is goal 3, "Good health and well-being" (21\%). Finally, the third to the last place is taken by goals 15 and 2, respectively "Life on land" and "Zero hunger", which appear to be far from the topics disclosed by the HEIs and involve $26 \%$ of the total sample.

The standard deviation analysis on the disclosed SDGs reveals a low variability within the 17 goals. Specifically, it is necessary to clarify that SDG 17, involving only two companies from the entire sample, represents an outlier for the analysis. On the contrary, the remaining part of the sample presents a certain homogeneity in terms of SDG disclosures, with a mean value of $40 \%$, showing how every SDG is disclosed by almost half of the sample.

\subsection{Disclosed SDG Themes}

The disclosure of the SDGs is also related to the description of the specific actions or objectives that the HEIs aim to follow. The automated coding operation on the collected reports allowed for the identification of different business topics related to the disclosure 
of the SDGs. In these terms, Table 4 provides an overview of such contents by identifying the ten most relevant themes.

Table 4. Top 10 SDGs-related themes.

\begin{tabular}{cc}
\hline Rank & Theme \\
\hline 1 & Environmental sustainability \\
2 & Strategy \\
3 & Professional development \\
4 & Year targets (e.g., emission goals, research goals) \\
5 & Ctudents' involvement \\
6 & Community engagement \\
7 & Energy efficiency \\
8 & Contribution to private companies \\
9 & Women directors \\
10 & Climate change \\
\hline
\end{tabular}

Confirming the insights collected through the analysis of the GRI indicators, the environmental sustainability topic leads the ranking by involving 14 coded paragraphs within the analysis.

However, the pursuit of social and environmental sustainability is linked to the planning operations. In this sense, the second place presents a certain coherence with the previous results by showing the relevance of the description of the strategic goal.

Furthermore, associated with the insights on the work safety and employee health GRI indicators, the disclosure of professional development topics reveals the strong concern of the sampled HEIs for SDG 8, "Decent work and economic growth".

The middle section of the ranking shows the social attitude of the HEIs by identifying "students' involvement" and "community engagement" as core topics in their SDGs disclosure sections.

Finally, the bottom part of the ranking provides some information related to the interest of HEIs in creating partnerships with private entities and in contributing to central CSR topics such as gender balance in the boards of directors and the struggle against climate change.

\section{Discussion and Conclusions}

The sustainable transition of the planet requires an in-depth reflection on the social role covered by entrepreneurs (Coronella et al. 2018; Sachs et al. 2019; Scheyvens et al. 2016). However, the implementation of sustainable practices should be driven by personal beliefs concerning the risks and opportunities related to adopting sustainable business models. The adherence to non-monetary purposes such as the equal division of profits between stakeholders and the involvement of local communities in decision-making processes cannot be achieved without cultural changes. In this sense, a central role could be performed by HEIs due to their leading position in the educational processes.

Evaluating the contribution provided by HEIs to the SDGs represents a critical issue for stakeholders (Cottafava et al. 2019; Leal Filho et al. 2019b). Although many academics agree with the strategic role covered by HEIs within society (Gusmão Caiado et al. 2018; Moggi 2019), the multidimensional character of the SDGs underlines the need to conduct specific reflections on them. Prior studies highlighted that the contribution made by any type of organization to Agenda 2030 is limited by the coexistence of positive, negative, and neutral interlinkages between the 17 SDGs (Bebbington and Unerman 2020; Nilsson et al. 2016). In this sense, even with the presence of a willingness to contribute to all the SDGs, specific goals will be prioritized more than others (Avrampou et al. 2019; Pizzi et al. 2021).

The development of the present study considered the development of the sustainability reports published by multiple HEIs that adopted the GRI standards as reporting guidelines. In these terms, the first part of the study tried to identify the core indicators considered by HEIs worldwide in order to find the most relevant sustainability issues for such entities. 
The results revealed how the sampled HEIs are mainly orienting their attention towards social issues. In these terms, the study appears to be in line with Carol Adams et al. (2014), confirming how sustainable change in the HEIs is seen in the struggle to fight against corruption and to promote gender diversity. However, the present study provides new insights regarding studies performed by Etse et al. (2021) and Alonso-Almeida et al. (2015), showing that the sampled HEIs appear to disclose environmentally related information in addition to the social topics.

Subsequently, the analysis explored the role and the level of SDG disclosure within the HEI context. As suggested by Beynaghi et al. (2016), the relevance of the relationship between SDGs and HEIs as recognized by SDG 4 has influenced the SDG disclosure of most HEIs. Moreover, the central role of HEIs in promoting equal and sustainable work environments (Ceulemans et al. 2015) is also revealed through the importance assigned to SDG 8, "Decent work and economic growth", and SDG 10, "Reduced inequalities".

Finally, the analysis of the SDG-related themes in the reports helped us to understand the explored topic further. Specifically, the need for an increased involvement of internal stakeholders (e.g., students) has found evidence in the promotion of student and community engagement events within the HEIs' strategic programs.

Accordingly, the present study has tried to contribute to the prior literature by suggesting a more comprehensive approach to SDGs reporting by HEIs. Specifically, by adopting a content analysis of the most recent sustainability reports, the present contribution has provided an overview of the SDGs that HEIs worldwide are working towards and has overcome the limitations of prior studies that have focused their attention only on certain cases or SDGs.

As with any research, the study is characterized by limitations. The first limitation consists of the analysis of a sample extracted from the Global Reporting Initiative database. Although the GRI leads the debate on sustainability reporting, many standards and guidelines have been developed to encourage HEIs to disclose their non-financial impacts. In this sense, future research could be addressed to filling this gap through a comparative analysis of the reports prepared according to the GRI standards and the reports prepared according to other national and international standards. The second limitation is represented by the time spam used in the present study. In this sense, the evolutionary pathway of each of the HEIs was not considered in our study. Thus, an empirical analysis based on panel data should serve as an effective tool to mitigate this criticism. Finally, future research could be addressed toward the filling of theoretical gaps about the disclosure of non-financial information through websites and social media (Nicolò et al. 2021).

Author Contributions: Conceptualization, F.C. and L.L.; methodology, S.P.; software, L.L.; validation, F.C.; formal analysis, L.L.; writing-original draft preparation, F.C., L.L., S.P.; writing-review and editing, F.C., L.L., S.P.; supervision, F.C.; project administration, F.C. All authors have read and agreed to the published version of the manuscript.

Funding: This research received no external funding.

Data Availability Statement: The data presented in this study are available on request from the corresponding author. The data are not publicly available due to reasons concerning privacy.

Conflicts of Interest: The authors declare no conflict of interest.

\section{References}

Adams, Carol A., Stephen Muir, and Zahirul Hoque. 2014. Measurement of sustainability performance in the public sector. Sustainability Accounting, Management and Policy Journal 5: 46-67. [CrossRef]

Adhikariparajuli, Mahalaxmi, Abeer Hassan, and Benedetta Siboni. 2021. Csr implication and disclosure in higher education: Uncovered points. results from a systematic literature review and agenda for future research. Sustainability 13: 525. [CrossRef]

Alexius, Susanna, and Giuseppe Grossi. 2018. Decoupling in the age of market-embedded morality: Responsible gambling in a hybrid organization. Journal of Management and Governance 22: 285-313. [CrossRef]

Alonso-Almeida, Maria del Mar, Frederic Marimon, Fernando Casani, and Jesus Rodriguez-Pomeda. 2015. Diffusion of sustainability reporting in universities: Current situation and future perspectives. Journal of Cleaner Production 106: 144-54. [CrossRef] 
An, Yi, Howard Davey, and Harun Harun. 2017. Sustainability reporting at a New Zealand public university: A longitudinal analysis. Sustainability 9: 1529. [CrossRef]

Aversano, Natalia, Ferdinando Di Carlo, Giuseppe Sannino, Paolo Tartaglia Polcini, and Rosa Lombardi. 2020. Corporate social responsibility, stakeholder engagement, and universities: New evidence from the Italian scenario. Corporate Social Responsibility and Environmental Management 27: 1892-99. [CrossRef]

Avrampou, Anna, Antonis Skouloudis, George Iliopoulos, and Nadeem Khan. 2019. Advancing the Sustainable Development Goals: Evidence from leading European banks. Sustainable Development 27: 743-57. [CrossRef]

Bebbington, Jan, and Jeffrey Unerman. 2018. Achieving the United Nations Sustainable Development Goals: An enabling role for accounting research. Accounting, Auditing and Accountability Journal 31: 2-24. [CrossRef]

Bebbington, Jan, and Jeffrey Unerman. 2020. Advancing research into accounting and the UN Sustainable Development Goals. Accounting, Auditing and Accountability Journal 33: 1657-70. [CrossRef]

Bellucci, Marco, and Giacomo Manetti. 2017. Facebook as a tool for supporting dialogic accounting? Evidence from large philanthropic foundations in the United States. Accounting, Auditing and Accountability Journal 30: 874-905. [CrossRef]

Beynaghi, Ali, Gregory Trencher, Fathollah Moztarzadeh, Masoud Mozafari, Reza Maknoon, and Walter Leal Filho. 2016. Future sustainability scenarios for universities: Moving beyond the United Nations Decade of Education for Sustainable Development. Journal of Cleaner Production 112: 3464-78. [CrossRef]

Brammer, Stephen, and Helen Walker. 2011. Sustainable procurement in the public sector: An international comparative study. International Journal of Operations and Production Management 31: 452-76. [CrossRef]

Brusca, Isabel, Margarita Labrador, and Manuel Larran. 2018. The challenge of sustainability and integrated reporting at universities: A case study. Journal of Cleaner Production 188: 347-54. [CrossRef]

Brusca, Isabel, Sandra Cohen, Francesca Manes-Rossi, and Giuseppe Nicolò. 2020. Intellectual capital disclosure and academic rankings in European universities: Do they go hand in hand? Meditari Accountancy Research 28: 51-71. [CrossRef]

Burke, Richard, and Istemi Demirag. 2015. Changing perceptions on PPP games: Demand risk in Irish roads. Critical Perspectives on Accounting 27: 189-208. [CrossRef]

Caputo, Fabio, and Nicola Di Cagno. 2010. La pubblica amministrazione e le sue modalità di funzionamento nel pensiero di Paolo Emilio Cassandro. Rivista Italiana Di Ragioneria e Di Economia Aziendale 5: 352-64.

Caputo, Fabio, Stefania Veltri, and Andrea Venturelli. 2017. A Conceptual Model of Forces Driving the Introduction of a Sustainability Report in SMEs: Evidence from a Case Study. International Business Research 10: 39. [CrossRef]

Carroll, Archie B. 2021. Corporate Social Responsibility: Perspectives on the CSR Construct's Development and Future. Business and Society 60: 1258-78. [CrossRef]

Ceulemans, Kim, Ingrid Molderez, and Luc Van Liedekerke. 2015. Sustainability reporting in higher education: A comprehensive review of the recent literature and paths for further research. Journal of Cleaner Production 106: 127-43. [CrossRef]

Coronella, Stefano, Fabio Caputo, Rossella Leopizzi, and Andrea Venturelli. 2018. Corporate social responsibility in Economia Aziendale scholars' theories: A taxonomic perspective. Meditari Accountancy Research 26: 640-56. [CrossRef]

Cottafava, Dario, Gabriela Cavaglià, and Laura Corazza. 2019. Education of sustainable development goals through students' active engagement: A transformative learning experience. Sustainability Accounting, Management and Policy Journal 10: 521-44. [CrossRef]

De La Poza, Elena, Paloma Merello, Antonio Barberá, and Alberto Celani. 2021. Universities' reporting on SDGs: Using the impact rankings to model and measure their contribution to sustainability. Sustainability 13: 2038. [CrossRef]

Di Nauta, Primiano, Enrica Iannuzzi, Michele Milone, and Claudio Nigro. 2020. The impact of the sustainability principles on the strategic planning and reporting of universities. An exploratory study on a qualified Italian sample. Sustainability $12: 7269$. [CrossRef]

Edwards-Jones, Andrew. 2014. Qualitative data analysis with NVIVO. Journal of Education for Teaching 40: 193-95. [CrossRef]

Esposito, Paolo, Spiridione Lucio Dicorato, and Emanuele Doronzo. 2021. The effect of ownership on sustainable development and environmental policy in urban waste management: An explicatory empirical analysis of Italian municipal corporations. Business Strategy and the Environment 30: 1067-79. [CrossRef]

Etse, Daniel, Adela McMurray, and Nuttawuth Muenjohn. 2021. Comparing sustainable public procurement in the education and health sectors. Journal of Cleaner Production 279: 123959. [CrossRef]

European Commission. 2014. Guide to Cost-benefit Analysis of Investment Projects: Economic appraisal tool for Cohesion Policy 2014-2020. In Publications Office of the European Union (Issue December). Brussels: European Commission. [CrossRef]

Filho, Walter Leal, João Henrique Paulino Pires Eustachio, Adriana Cristina Ferreira Caldana, Markus Will, Amanda Lange Salvia, Izabela S. Rampasso, Rosley Anholon, Johannes Platje, and Marina Kovaleva. 2020. Sustainability leadership in higher education institutions: An overview of challenges. Sustainability 12: 3761. [CrossRef]

García Meca, Emma, and Jennifer Martínez Ferrero. 2021. Is SDG reporting substantial or symbolic? An examination of controversial and environmentally sensitive industries. Journal of Cleaner Production 298: 126781. [CrossRef]

García-Feijoo, María, Almudena Eizaguirre, and Alvaro Rica-Aspiunza. 2020. Systematic Review of Sustainable-Development-Goal Deployment in Business Schools. Sustainability 12: 440. [CrossRef]

GBS. 2005. La Rendicontazione Sociale nel Settore Pubblico. Available online: http:/ /www.gruppobilanciosociale.org/pubblicazioni/ la-rendicontazione-sociale-nel-settore-pubblico/ (accessed on 31 July 2021). 
GBS. 2008. La Rendicontazione Sociale nelle Università-Documenti di Ricerca n. 7. Available online: http:/ / www.gruppobilanciosociale. org/pubblicazioni/la-rendicontazione-sociale-nelle-universita-documenti-di-ricerca-n-7/ (accessed on 31 July 2021).

Global Reporting Initiative. 2017. SDG Compass Annex: Linking the SDGs and GRI Standards. Amsterdam: Global Reporting Initiative. GRI. 2020. Linking the SDGs and GRI Standards. In GRI Supports the Sustainable Development Goals. Amsterdam: GRI.

Gulluscio, Carmela, and Patrizia Torrecchia. 2017. Corporate Social Responsibility in the University Courses in Italy: An Empirical Analysis. Cham: Springer, pp. 139-65. [CrossRef]

Gusmão Caiado, Rodrigo Goyannes, Walter Leal Filho, Osvaldo Luiz Gonçalves Quelhas, Daniel Luiz de Mattos Nascimento, and Lucas Veigas Ávila. 2018. A literature-based review on potentials and constraints in the implementation of the sustainable development goals. Journal of Cleaner Production 198: 1276-88. [CrossRef]

Jackson, Kristi, and Pat Bazeley. 2020. Qualitative Data Analysis with NVivo, 3rd ed. Newcastle upon Tyne: SAGE.

Jain, Ameeta, and Muhammad Azizul Islam. 2015. A preliminary analysis of the impact of un MDGs and Rio+20 on corporate social accountability practices. Developments in Corporate Governance and Responsibility 8: 81-102. [CrossRef]

Krippendorff, Klaus. 2018. Content Analysis, 4th ed. Newcastle upon Tyne: SAGE.

Leal Filho, Walter, Chris Shiel, Arminda Paço, Mark Mifsud, Lucas Veiga Ávila, Luciana Londero Brandli, Petra Molthan-Hill, Paul Pace, Ulisses M. Azeiteiro, Valeria Ruiz Vargas, and et al. 2019a. Sustainable Development Goals and sustainability teaching at universities: Falling behind or getting ahead of the pack? Journal of Cleaner Production 232: 285-94. [CrossRef]

Leal Filho, Walter, Valeria Ruiz Vargas, Amanda Lange Salvia, Luciana Londero Brandli, Eric Pallant, Maris Klavins, Subhasis Ray, Sara Moggi, Marija Maruna, Elisa Conticelli, and et al. 2019b. The role of higher education institutions in sustainability initiatives at the local level. Journal of Cleaner Production 233: 1004-15. [CrossRef]

Lee, W. Eric, and Amy M. Hageman. 2018. Talk the Talk or Walk the Walk? An Examination of Sustainability Accounting Implementation. Journal of Business Ethics 152: 725-39. [CrossRef]

Lozano, Rodrigo. 2006. A tool for a Graphical Assessment of Sustainability in Universities (GASU). Journal of Cleaner Production 14: 963-72. [CrossRef]

Manes Rossi, Francesca, Giuseppe Nicolò, and Paolo Tartaglia Polcini. 2018. New trends in intellectual capital reporting: Exploring online intellectual capital disclosure in Italian universities. Journal of Intellectual Capital 19: 814-35. [CrossRef]

Michelon, Giovanna, Dennis M. Patten, and Andrea M. Romi. 2019. Creating Legitimacy for Sustainability Assurance Practices: Evidence from Sustainability Restatements. European Accounting Review 28: 395-422. [CrossRef]

Midin, Mariam, Corina Joseph, and Nafsiah Mohamed. 2017. Promoting societal governance: Stakeholders' engagement disclosure on Malaysian local authorities' websites. Journal of Cleaner Production 142: 1672-83. [CrossRef]

Moggi, Sara. 2019. Social and environmental reports at universities: A Habermasian view on their evolution. Accounting Forum 43: 283-326. [CrossRef]

Navarro Galera, Andrés, Araceli de los Ríos Berjillos, Mercedes Ruiz Lozano, and Pilar Tirado Valencia. 2014. Transparency of sustainability information in local governments: English-speaking and Nordic cross-country analysis. Journal of Cleaner Production 64: 495-504. [CrossRef]

Nicolò, Giuseppe. 2020. The Rise of Intellectual Capital Disclosure from Private to Public Sector: The Case of Italian Public Universities. Milano: Franco Angeli.

Nicolò, Giuseppe, Giuseppe Sannino, and Serena De Iorio. 2021. Gender diversity and online intellectual capital disclosure: Evidence from Italian-listed firms. Journal of Public Affairs, e2706. [CrossRef]

Nilsson, Måns, Dave Griggs, and Martin Visbeck. 2016. Policy: Map the interactions between Sustainable Development Goals. Nature 534: 320-22. [CrossRef] [PubMed]

Pizzi, Simone, Andrea Caputo, Antonello Corvino, and Andrea Venturelli. 2020. Management research and the UN sustainable development goals (SDGs): A bibliometric investigation and systematic review. Journal of Cleaner Production 276: 124033. [CrossRef]

Pizzi, Simone, Francesco Rosati, and Andrea Venturelli. 2021. The determinants of business contribution to the 2030 Agenda: Introducing the SDG Reporting Score. Business Strategy and the Environment 30: 404-21. [CrossRef]

Raji, Abdulhakeem, and Abeer Hassan. 2021. Sustainability and stakeholder awareness: A case study of a Scottish university. Sustainability 13: 4186. [CrossRef]

RUS, and GBS. 2021. Il Bilancio di Sostenibilità delle Università. Available online: http:/ / www.gruppobilanciosociale.org/wp-content/ uploads/2021/04/RUS-GBS-standard_DEF.pdf (accessed on 31 July 2021).

Sachs, Jeffrey D. 2012. From millennium development goals to sustainable development goals. The Lancet 379: 2206-11. [CrossRef]

Sachs, Jeffrey D., Guido Schmidt-Traub, Mariana Mazzucato, Dirk Messner, Nebojsa Nakicenovic, and Johan Rockström. 2019. Six transformations to achieve the sustainable development goals. Nature Sustainability 2: 805-14. [CrossRef]

Saha, Anup Kumar, Habiba Al-Shaer, Rob Dixon, and Istemi Demirag. 2021. Determinants of Carbon Emission Disclosures and UN Sustainable Development Goals: The Case of UK Higher Education Institutions. Australian Accounting Review 31: 79-107. [CrossRef]

Salvia, Amanda Lange, Walter Leal Filho, Luciana Londero Brandli, and Juliane Sapper Griebeler. 2019. Assessing research trends related to Sustainable Development Goals: Local and global issues. Journal of Cleaner Production 208: 841-49. [CrossRef] 
Sannino, Giuseppe, Manuela Lucchese, Giovanni Zampone, and Rosa Lombardi. 2020. Cultural dimensions, Global Reporting Initiatives commitment, and corporate social responsibility issues: New evidence from Organisation for Economic Co-operation and Development banks. Corporate Social Responsibility and Environmental Management 27: 1653-63. [CrossRef]

Sassen, Remmer, and Leyla Azizi. 2018. Voluntary disclosure of sustainability reports by Canadian universities. Journal of Business Economics 88: 97-137. [CrossRef]

Scheyvens, Regina, Glenn Banks, and Emma Hughes. 2016. The Private Sector and the SDGs: The Need to Move Beyond 'Business as Usual'. Sustainable Development 24: 371-82. [CrossRef]

Sepasi, Sahar, Udo Braendle, and Amir Hossein Rahdari. 2019. Comprehensive sustainability reporting in higher education institutions. Social Responsibility Journal 15: 155-70. [CrossRef]

Steurer, Reinhard, Andre Martinuzzi, and Sharon Margula. 2012. Public Policies on CSR in Europe: Themes, Instruments, and Regional Differences. Corporate Social Responsibility and Environmental Management 19: 206-27. [CrossRef]

United Nations. 2015. Transforming Our World: The 2030 Agenda for Sustainable Development. A/RES/70/1. In United Nations (Issue October). New York: United Nations, vol. 16301.

Venturelli, Andrea, and Fabio Caputo. 2017. Informativa non Finanziaria e Regulation: Tendenze Evolutive e Relative Implicazioni alla luce Dell'emanazione del D. Lgs 254/16 (I). New York: McGraw Hill.

Venturelli, Andrea, Fabio Caputo, and Stefano Adamo. 2019a. SDG accounting e informativa non finanziaria: Prime evidenze empiriche sul contesto Italiano. In Nuove Frontiere del Reporting Aziendale. La Comunicazione agli Stakeholders tra Vincoli Normativi e Attese Informative. Edited by Silvano Corbella, Luciano Marchi and Francesca Rossignoli. Milan: Franco Angeli.

Venturelli, Andrea, Fabio Caputo, and Simone Pizzi. 2019b. L'offerta di contenuti di responsabilità sociale negli atenei italiani. Un' analisi esplorativa. Rivista Italiana Di Ragioneria e Di Economia Aziendale. [CrossRef]

Voorn, Bart, Marieke L. Van Genugten, and Sandra Van Thiel. 2017. The efficiency and effectiveness of municipally owned corporations: A systematic review. Local Government Studies 43: 820-41. [CrossRef] 